\title{
A ERA PÓS-MÉTODO: O PROFESSOR COMO UM INTELECTUAL
}

\author{
Gisvaldo Araújo Silva \\ mesufsm@yahoo.com.br
}

\section{RESUMO}

Neste artigo, pretende-se discutir as idéias de alguns princípios pedagógicos, baseados nas observações em sala de aula e na literatura em Lingüística Aplicada, no ensino de línguas estrangeiras (LE) do que se convencionou chamar de PósMétodo. Para tal, começa-se discutindo a mudança no status dos métodos e abordagens no ensino de LE e os perigos de se adotar um único método ou abordagem como ideal para todos os contextos, em seguida destacam-se as contribuições que conhecimento de vários métodos e abordagens podem dar para os(as) professores(as) de LE, depois são discutidas as propostas feitas pelos principais autores da área, enfatizando a necessidade de uma mudança de postura na atitude do(a) professor(a) e, por fim, conclui-se argumentando que apenas por meio de sua qualificação continuada, reflexão sobre seu trabalho e observação de aspectos contextuais, o(a) professor(a) vai ser capaz de fazer julgamentos, a partir da teoria e de sua prática, e sugerir alternativas para um ensino de LE mais efetivo.

\section{MÉTODOS, ABORDAGENS E O ENSINO DE LÍNGUA ESTRANGEIRA}

Apesar dos avanços na Lingüística e do surgimento da Lingüística Aplicada que, dentre outros temas, enfoca o ensino de línguas e, mais especificamente, o ensino de LE, os métodos e as abordagens, ou até mesmo a aplicação ineficaz dos mesmos, têm sido considerados como responsáveis pelos baixos resultados obtidos no ensino de LE (Richards \& Rodgers, 2001, p. 244). Os profissionais da área, que muitas vezes carecem de uma formação lingüística adequada, continuam em busca de uma fórmula mágica que dê conta de um processo tão complexo e que engloba tantas variáveis como o ensino/aprendizagem de LE.

Segundo Brown (1997) - que parece trazer definições mais consistentes do que seus colegas - Abordagem é entendida como "posições teóricas e crenças sobre a natureza da linguagem, a natureza da aprendizagem de línguas e a aplicabilidade de ambas no contexto pedagógico", enquanto que Método é entendido como "um conjunto geral e prescrito de especificações da sala de aula para se atingir objetivos lingüísticos. Os métodos tendem a estar relacionados, em primeiro plano, com o papéis e comportamentos de professores(as) e alunos(as) e, em segundo plano, com aspectos tais como objetivos lingüísticos e de conteúdo, ordem dos assuntos e materiais utilizados [...]". 
Novos métodos e abordagens têm surgido (Content-Based Instruction, Multiple Intelligences e Cooperative Learning), alguns têm resistido ao tempo (GrammarTranslation e AudioLingual), outros desaparecem quase sem deixar vestígios (Silent Way e Sugestiologia de Lozanov, por exemplo), contudo nenhum deles e capaz de dar conta, ou explicar o processo de aprendizagem de LE em sua totalidade (LarsenFreeman, 2000, p. 186; Richards \& Rodgers, 2001, p. 159).

\section{CONTROVÉRSIAS:}

Em geral, os métodos e abordagens são apresentados como soluções para problemas de ensino que podem ser aplicados em qualquer lugar e em qualquer circunstância (Brown, 1997; Larsen-Freeman, 2000). No entanto, não se deve perder de vista que fatores contextuais são fundamentais numa implementação criteriosa de uma corrente de ensino ou de qualquer programa de ensino em geral. Richards \& Rodgers citam "contexto cultural, contexto político, institucional local, e o contexto constituído pelos professores(as) e aprendizes na sala de aula" como critérios a serem levados em consideração na decisão de uma política de ensino (2001, p. 248).

Um dos problemas com os métodos é que "[o] bom ensino é considerado aquele que usa corretamente o método, seus princípios e técnicas preestabelecidas" (idem, p. 247). Nessa perspectiva, não se considera o papel ativo do aprendiz, nem suas crenças, estilos, preferências, objetivos, necessidades e interesses. O mesmo, em geral, acontece em relação aos(às) professores(as) que ficam limitados(as) a reproduzir modelos e receitas que não permitem análises críticas e não consideraram fatores como experiência do profissional, objetivos, desejos, motivações, etc.

Já em relação às abordagens, elas têm sido modificadas, sofrendo adaptações, principalmente por se tratarem de concepções mais flexíveis (Brown, 1997; Richards \& Rodgers, 2001). Tal fato pode ter um valor positivo, quando estas adaptações dizem respeito a considerar fatores culturais e o contexto dos aprendizes (Kumaravadivelu, 1994) ou um valor negativo quando simplesmente passam a ser "um conjunto de princípios muito gerais que podem ser aplicados e adaptados de maneiras bem 
variadas" - o que aconteceu com a Abordagem Comunicativa (Comunicative Language Teaching) de acordo com Richards \& Rodgers (2001, p. 245).

Contrapondo método e abordagem, pode-se perceber que a tendência é que o método goze de prestígio por um tempo mais curto do que as abordagens, visto que aquele tem um formato fechado e não permite mudanças ou adaptações, em contrapartida o caráter mais flexível destas faz com que elas irritem e frustrem professores(as) recémformados(as), especialmente, por que as abordagens não trazem instruções concretas de como proceder na sala de aula (Richards \& Rodgers, 2001, p. 246).Os autores citados acima destacam que "os métodos e abordagens geralmente se baseiam na premissa de que os processos de aprendizagem de línguas são compreendidos em sua totalidade", (idem, p. 249) de forma que grande parte dos argumentos usados como verdades e fatos pelos defensores de algumas correntes não foram empiricamente testados ou possuem uma base teórica questionável.

Os lingüistas supracitados, usando como base um estudo realizado por Swaffar, Arens \& Morgan, argumentam que outro fator a se levar em consideração é a dificuldade que os professores(as) encontram em usar as abordagens e métodos que reflitam precisamente seus princípios, fazendo com que fatores distintivos entre métodos desapareçam na hora de colocá-los em prática, especialmente em estágios mais avançados. Na mesma linha, Kumaravadivelu cita um estudo no qual até mesmo os produtores de livros e os elaboradores de currículo não seguem a risca a filosofia do método que defendem (1994, p. 30). Outro autor que discute essa questão é Brown (1997), ele destaca que o que parece ser distintivo nos primeiros estágios de cada método e abordagem acaba desaparecendo nos estágios mais avançados.

Pode-se perceber, então, que a pesquisa em Lingüística Aplicada tem constatado que as controvérsias presentes tanto nas concepções quanto na aplicação dos métodos e abordagens alertam o(a) professor(a) sobre a complexidade do tema e o/a impele a uma reflexão acerca da escolha de seus princípios e técnicas de trabalho.

\section{CONTRIBUIÇÕES DOS MÉTODOS E ABORDAGENS:}

Apesar das incoerências e controvérsias dos métodos e abordagens, a literatura argumenta que eles podem contribuir de várias maneiras para a formação e 
atualização do(a) professor(a), Richards \& Rodgers (2001, p. 350) apontam alguns possíveis benefícios de estudá-los e conhecê-los bem que estão sintetizados aqui: saber quais métodos e abordagens são adequados em determinada situação; entender algumas controvérsias que caracterizam a história do ensino de línguas; experimentar abordagens e métodos diferentes e usá-los como base para reflexão e comparação; ter várias fontes de atividades disponíveis para um usá-las criativamente; entender que a relação entre teoria e prática pode ser justificada por várias perspectivas diferentes.

Larsen-Freeman (2000, p. XI) parece ser mais objetiva nessa questão, indo diretamente a uma concepção central no Pós-Método, a autora argumenta que além de propiciar a reflexão, por meio do conhecimento dos métodos e abordagens, podese trazer para o nível consciente os pensamentos que estão por trás das ações preconizadas por eles. Isso pode [e deve] fazer com que os(as) professores(as) se conscientizem de suas suposições, seus valores e suas crenças. A partir daí, eles podem tomar decisões que são baseadas na reflexão e não condicionadas às suas experiências enquanto aluno(a) e professor(a).

Em resumo, apesar da mudanças no status dos termos abordagem e método, os autores supracitados concluem que campo de ensino de línguas promete ser tão criativo e original como o tem sido por um bom tempo. É interessante que o(a) professor(a) seja capaz de identificar os princípios que regem os métodos e abordagens, quais deles são coerentes com as suas concepções (que devem ser fruto de questionamentos) e realidade, a partir de sua experiência e conhecimento teórico, tente inferir em que contexto eles podem propiciar bons resultados.

\section{PRINCÍPIOS E PROPOSTAS DO PÓS-MÉTODO:}

Devido aos avanços das pesquisas da área e todas as controvérsias dos métodos e abordagens, pesquisadores no início da década de 1990 (Prabhu, 1990; Allwright, 1991) questionaram duramente a aplicabilidade de um único método como resposta para o ensino de línguas estrangeiras. Em 1994, Kumaravadivelu publicou no periódico TESOL Quarterly um artigo no qual estabelecia as bases do que ele chama de Condição Pós-Método. Ele define esta condição como "um estado que nos compele a redefinir a relação entre os teóricos e aqueles que praticam um 
determinado método" (p. 28). O ensino de LE tem sempre sofrido posição pendulares que ora tinham como foco o(a) professor(a), ora o aprendiz, e ora o processo de aprendizagem, entretanto, a tendência predominante era a de que havia um grupo que pensava no ensino e outro que ensinava. As decisões eram sempre tomadas pelos pesquisadores e aos(às) professores(as) cabia apenas acatá-las. Criava-se então um abismo entre a teoria e a prática.

Brown (1997) propôs um ecletismo esclarecido no qual o(a) professor(a) escolheria entre os métodos e abordagens as atividades que mais o interessasse e que tinha surtido efeito em aulas anteriores, o que é condenando por Kumaravadivelu (1994, p. 30) "ecletismo na sala de aula, invariavelmente, transforma-se numa pedagogia assistemática, acrítica e sem princípios, porque os(as) professores(as) com pouco preparo profissional para serem criteriosamente ecléticos, têm poucas opções, além de reunir um amontoado de técnicas de vários métodos diferentes aleatoriamente e chamá-lo de eclético". É bastante possível que o autor esteja sendo radical em sua colocação, além do mais o que os autores defendem é o Ecletismo Esclarecido e não o ecletismo per se. Ele esquece que há muito mais consonâncias do que divergência entre a suas idéias e aquelas defendidas por Brown (Para efeito de comparação, ver Tabela 1). O que mais diferencia Kumaravadivelu (assim como Giroux e Kincheloe) dos outros autores citados neste artigo em relação ao Pós-Método é que ele vai além da combinação de métodos e abordagens para construção de uma abordagem própria. Esse autor enfatiza a importância de uma mudança na postura do(a) professor(a). Ele destaca que além de aliar sua prática pedagógica a pesquisas da área, deve-se trabalhar numa perspectiva ecológica na qual estão envolvidos professores(as), formadores(as) de professor(a), contexto político, sócio-econômico, além dos objetivos específicos dos(as) alunos(as).

Em 2001, Kumaravadivelu revê os princípios da pedagogia Pós-Método, apresentados no seu artigo de 1994, chamando atenção para a autonomia do aprendiz tanto no âmbito acadêmico quanto no âmbito social. Ele indica algumas atitudes que devem ser tomadas pelo(a) professor(a), pelos seus/suas colegas de trabalho que podem auxiliar na tomada de maior responsabilidade, além de uma tomada de consciência por parte do(a) aluno(a) sobre seu processo de aprendizagem. $\mathrm{O}$ autor centrou seu estudo em três figuras que têm papéis fundamentais no processo 
de ensino/aprendizagem, os aprendizes, os(as) professores(as) e os formadores de professores(as), descrevendo a postura de cada um nesta nova condição.

Nessa perspectiva, o papel do(a) professor(a) não se resume a selecionar conteúdo e escolher técnicas para aplicá-los, ele também pode possibilitar que os aprendizes reflitam sobre seu papel na sociedade, como a linguagem está estruturada e a que interesses ela serve. O trabalho em duplas e grupos pode ajudar a formar uma comunidade na qual o aprendiz pode se conscientizar do seu papel e passar a encarar o trabalho em equipe sob uma nova ótica. O que parece mais interessante aqui é que o autor passa a destacar as questões sócio-políticas que envolvem o ensino em geral e conseqüentemente o ensino/aprendizagem de LE, vendo a prática pedagógica como instrumento para a construção da cidadania do(a) aluno(a).

Nessa nova concepção, a pesquisa passa a ter como foco a sala de aula, de forma que a abordagem do(a) professor(a) vai se construindo a partir de uma dinâmica entre a realidade deste, de seus/suas alunos(as) e a partir dos indícios e resultados de pesquisas da área, sejam elas de natureza teórica, empírica ou pedagógica. Sendo assim, o(a) professor(a) se torna um pesquisador capaz de indicar em que medida os achados da teoria auxiliam a sua prática. Isso pode possibilitar que ele tenha instrumentos que contribuam para que o mesmo aponte alternativas e faça adaptações capazes de surtir efeitos na sua sala de aula.

Inicialmente, Kumaravadivelu (1994) desenvolveu um modelo teórico que engloba 10 macro-estratégias (tabela 1.0, coluna 3). Elas são entendidas como "planos gerais que provêem do conhecimento teórico, empírico e pedagógico relativos ao processo de ensino/aprendizagem de LE" (p.32). A partir da experiência e do ganho de conhecimento, o(a) professor(a) vai ser capaz de desenvolver uma abordagem própria que poderá partir de um método ou abordagem preexistente, mas que refletirá suas crenças, valores, princípios e experiências. O pesquisador chama a atenção para que se considere o contexto e uma série de outros fatores que influenciam e contribuem para o ensino de LE. Assim como esse lingüista, outros autores também discutem as propostas do que se convencionou chamar de Pós-Método e o papel do(a) professor(a) nesta nova perspectiva. A tabela abaixo indica as estratégias a serem implementadas na sala de aula segundo três estudiosos diferentes: 


\begin{tabular}{|c|c|c|}
\hline $\begin{array}{l}\text { Richards \& Rodgers } \\
\text { 2001) }\end{array}$ & Brown (1997) & Kumaravadivelu (1994) \\
\hline $\begin{array}{l}1 \text { - Envolva todos os } \\
\text { alunos na lição; }\end{array}$ & Diminua a inibição; & Garanta relevância social; \\
\hline $\begin{array}{l}2 \text { - Seja tolerante aos } \\
\text { erros dos alunos; }\end{array}$ & $\begin{array}{l}\text { Encoraje a tomada de } \\
\text { riscos; }\end{array}$ & $X$ \\
\hline $\begin{array}{l}3 \text { - Desenvolva a auto- } \\
\text { confiança dos alunos; }\end{array}$ & $\begin{array}{l}\text { "Aumente" a } \\
\text { autoconfiança dos alunos; }\end{array}$ & $\begin{array}{l}\text { Desenvolva a consciência } \\
\text { cultural do aprendiz; }\end{array}$ \\
\hline $\begin{array}{l}4 \text { - Desenvolva a respon- } \\
\text { sabilidade no aluno; }\end{array}$ & $X$ & $\begin{array}{l}\text { Promova a autonomia do } \\
\text { aluno; }\end{array}$ \\
\hline $\begin{array}{l}5 \text { - Use o máximo de } \\
\text { atividades em duplas, } \\
\text { grupos; }\end{array}$ & $X$ & $\begin{array}{l}\text { Facilite a interação } \\
\text { negociada; }\end{array}$ \\
\hline $\begin{array}{l}6 \text { - Faça dos alunos e não } \\
\text { do professor o centro da } \\
\text { aula; }\end{array}$ & $\begin{array}{l}\text { Encoraje os alunos a } \\
\text { usarem processos que } \\
\text { utilizem o hemisfério } \\
\text { direito do cérebro; }\end{array}$ & $\begin{array}{l}\text { Contextualize o insumo } \\
\text { lingüístico; }\end{array}$ \\
\hline $\begin{array}{l}7 \text { - Ensine estratégias de } \\
\text { aprendizagem; }\end{array}$ & $\begin{array}{l}\text { Ajude os alunos a usarem } \\
\text { a intuição; }\end{array}$ & Ative a heurística intuitiva; \\
\hline $\begin{array}{l}8 \text { - Responda às dificul- } \\
\text { dades dos alunos e } \\
\text { trabalhe em cima delas; }\end{array}$ & $\begin{array}{l}\text { Faça com que os erros } \\
\text { dos alunos possam } \\
\text { contribuir para o processo } \\
\text { de aprendizagem; }\end{array}$ & $\begin{array}{l}\text { Promova o desenvol- } \\
\text { vimento da consciência } \\
\text { lingüística; }\end{array}$ \\
\hline $\begin{array}{l}9 \text { - Forneça o máximo de } \\
\text { oportunidades para a } \\
\text { participação dos alunos; }\end{array}$ & $\begin{array}{l}\text { Ajude os alunos a } \\
\text { desenvolverem a } \\
\text { motivação intrínseca; }\end{array}$ & $\begin{array}{l}\text { Maximize as oportuni- } \\
\text { dades de aprendiza-gem; }\end{array}$ \\
\hline $\begin{array}{l}10 \text { - Promova a coope- } \\
\text { ração entre os apren- } \\
\text { dizes; }\end{array}$ & $\begin{array}{l}\text { Promova aprendizagem } \\
\text { cooperativa; }\end{array}$ & $\begin{array}{l}\text { Integre as quatro } \\
\text { habilidades; }\end{array}$ \\
\hline $\begin{array}{l}11 \text { - Pratique tanto } \\
\text { fluência quanto correção } \\
\text { grama-tical; }\end{array}$ & $\begin{array}{l}\text { Promova tolerância à } \\
\text { ambigüidade; }\end{array}$ & Minimize mal-entendi-dos. \\
\hline $\begin{array}{l}12 \text { - Direcione as neces- } \\
\text { sidades e interesses dos } \\
\text { alunos. }\end{array}$ & $\begin{array}{l}\text { Faça com que os alunos } \\
\text { estabeleçam seus } \\
\text { próprios objetivos. }\end{array}$ & $X$ \\
\hline
\end{tabular}

Tabela 1.0: Comparação entre três autores dos princípios que "devem" fazer parte da aula do(a) professor(a) de línguas em constante atualização. 
Embora Brown (1997) não adote o termo Pós-Método e prefira usar Ecletismo Esclarecido, observando a Tabela 1.0, pode-se perceber que os três autores convergem em vários pontos. O que Brown chama de técnicas estratégicas, ou os "dez mandamentos" de uma boa aprendizagem de línguas (aspas do autor), parece estar em consonância com as propostas de Kumaravadivelu (1994), assim como as de Richards \& Rodgers (2001) em relação ao Pós-Método. Para facilitar a visualização, procurou-se organizar os itens a partir de pontos em comum, ou complementares.

Por meio da tabela, pode-se observar que alguns itens querem dizer basicamente a mesma coisa, por exemplo, os de número 7 comparando Brown e Kumaravadivelu: Ajude os alunos a usarem a intuição e Ative a heurística intuitiva são expressões sinônimas e os de número 9 comparando Richards \& Rodgers e Kumaravadivelu: Forneça o máximo de oportunidades para a participação dos alunos e Maximize as oportunidades de aprendizagem também querem dizer a mesma coisa.

Outros se complementam: os itens de número 1 nos três autores: afinal para [e]nvolv[er] todos os alunos na lição é necessário que o(a) professor(a) [g]aranta relevância social e diminua a inibição dos eventuais alunos(as) tímidos(as) ou daqueles que, por algum motivo, se sintam pouco a vontade para participar de uma determinada aula; os de número 2: comparando Kumaravadivelu e Brown: Seja tolerante aos erros dos alunos e Encoraje a tomada de riscos - parece razoável que o(a) professor(a) que enxerga a importância de os(as) alunos(as) descobrirem como a LE funciona por eles mesmos, entenda que os desvios (tradicionalmente chamados de erros) fazem parte desse processo e, portanto, não devem ser evitados, já que podem servir de meio para se chegar a uma competência comunicativa mais adequada.

Alguns itens, apesar de parecerem diferentes, numa análise mais atenta, apresentam uma conexão, os de número 11 são bons exemplos: Promova tolerância à ambigüidade, Brown (1997) parece ter se equivocado na nomenclatura deste item, pois ao comentar como o(a) professor(a) pode auxiliar o aluno(a) a desenvolver essa estratégia, ele diz "encoraje os alunos a lhe perguntar, e a perguntar aos colegas quando eles não entenderem alguma coisa; procure dar explicações teóricas simples e objetivas [...]" (p. 131). Parece haver uma inconsistência aqui, pois fazer perguntas, interagir com os colegas, dar explicações claras e objetivas são estratégias utilizadas 
para desfazer ambigüidades e incertezas e não estratégias usadas para que o(a) aluno(a) se sinta mais confortável com as incertezas e ambigüidades características do processo comunicativo. Nesse sentido, essa estratégia parece estar diretamente relacionada a macro-estratégia proposta por Kumaravadivelu: Minimize malentendidos.

Existe ainda um quarto grupo de itens que, embora nem queiram dizer a mesma coisa, nem sejam correspondentes, e nem se mostrem aparentemente diferentes, mas se revelem bastante parecidos se examinados mais atentamente, parecem estar de acordo com essa condição de que o(a) professor(a) em conjunto com o aluno(a) pode propiciar um ambiente onde a LE passa a servir de instrumento para promover a comunicação. Esse é caso dos itens sob número 6, por exemplo.

Listas desse tipo não devem ser consideradas como receitas a serem seguidas a risca na aula de LE, e, apesar do uso do imperativo, parece mais adequado que elas sejam vistas como possibilidades de atitudes a serem adotadas em sala de aula. $O(A)$ professor(a) deve ser criterioso(a) ao avaliar quais dessas posturas podem ser incorporadas e que princípios vão de encontro com as suas crenças e realidades. Mais do que prescrições, essas propostas podem servir para que o(a) professor(a) reflita sobre sua prática, observe seu contexto, teorize e avalie sua abordagem de ensino.

Segundo Kumaravadivelu "Todas as práticas em sala de aula refletem os princípios e crenças dos(as) professores(as), e sistemas diferentes de crenças entre professores(as) pode, freqüentemente, explicar porque os(as) professores(as) dão suas aulas de formas diferentes" (2001, p. 351).

\section{IMPLICAÇÕES:}

Conforme Kumaravadivelu: "[e]m termos práticos, a condição pós-método cria a necessidade de um modelo coerente e em construção baseado em insights teóricos vigentes, empíricos e pedagógicos que ativem e desenvolvam o sentido de plausibilidade dos professores e criem um sentido de envolvimento" (1994, p.44). Posto isto, o(a) professor(a) deve desenvolver uma educação sensível ao contexto que possibilite a construção de suas próprias teoria e prática. Esse autor (no artigo de 2001) vê o Pós-Método como um sistema tridimensional que consiste em 3 
parâmetros pedagógicos: particularidade, praticidade e possibilidade. A pedagogia da particularidade parte da perspectiva de que um ensino significativo, "não pode ser alcançado sem uma interpretação das situações específicas e não pode ser melhorado sem que haja uma melhora geral dessas situações específicas" (p. 538539); o lingüista defende que para ser relevante, a pedagogia deve ser sensível ao grupo de professores(as) e alunos(as) aos quais ela está direcionada, levando em consideração os objetivos, o contexto e fatores sócio-culturais.

A pedagogia da prática não diz respeito apenas a prática pedagógica, mas a relação existente entre teoria e prática. Comumente tem-se divido o primeiro item em duas categorias: 1- Teoria dos especialistas - fruto de pesquisas nos grandes centros de produção intelectual - que goza de um prestígio maior; e 2- Teoria dos professores(as) - baseia-se nas crenças que os(as) professores(as) desenvolvem quando interpretam e aplicam a teoria nas aulas que ministram. Essa dinâmica limita o trabalho do(a) professor(a) a mero consumidor de pesquisas, deixando "pouquíssimo espaço para a formulação de seus próprios conceitos e construção de um conhecimento pedagógico, porque os(as) professores(as) são vistos meramente como aqueles que implementam teorias de profissionais." (idem, p. 540-1).

A pedagogia da possibilidade parte do pressuposto, defendido por Paulo Freire, de que qualquer pedagogia está baseada em relações de poder e domínio, sendo implementada para criar e manter desigualdades sociais. Tendo isso em mente, o pesquisador sugere os princípios da Pedagogia do Oprimido que implica (de forma bem resumida) no questionamento do status quo e na possibilidade de mudança dessa condição por meio da conscientização dos(as) alunos(as) e de ações concretas no (s) meio(s) onde eles vivem (Giroux, 1997).

\section{O/A PROFESSOR/A COMO INTELECTUAL:}

Richards \& Rodgers (2001) indicam que há muito mais para o desenvolvimento de um(a) professor(a) que aprender a usar abordagens e métodos diferentes de ensino. No entanto, estes podem servir como base para que o(a) professor(a) reflita sobre sua prática. Esse "muito mais" referido pelos autores supracitados, pode ser entendido como o engajamento na produção de materiais didáticos adequados ao contexto sócio-cultural no qual o(a) professor(a) está inserido, pode ser também um chamado 
para que o(a) professor(a) desenvolva um nível de conhecimento capaz de o/a tornar produtor(a) de conhecimento e não um(a) mero reprodutor(a) de fórmulas prontas que, em geral, não se adaptam ao seu contexto (Giroux, 1997b, p. 160-1) .

Kumaravadivelu (1994, p. 43) enfatiza que o enquadramento teórico não tem objetivo prescritivo, mas se apresenta como um leque de opções que pode servir como ponto de partida para uma reflexão sobre a prática pedagógica. Para que esta reflexão ocorra, recomenda-se que o(a) professor(a) considere os seguintes aspectos:

\begin{abstract}
[A]s necessidades específicas, desejos, situações e os processos de ensino/aprendizagem, ampliação de conhecimento, habilidade e atitude para estar informado; exploração e extensão das macro-estratégias para que elas dêem conta dos desafios e mudanças de contexto do ensino; desenvolvimento de micro-estratégias apropriadas para maximizar 0 potencial de aprendizagem na sala de aula, e monitoramento de sua habilidade de reagir as mais diversas situações de maneira significativa.
\end{abstract}

Em consonância com essas idéias, no artigo de Kumaravadivelu (2001, p. 537), além da limitação do termo método e um chamado para se encontrar uma forma alternativa de desenvolver estratégias de ensino efetivas, há uma ênfase na necessidade de se ir além das limitações de um modelo de transmissão de educação do(a) professor(a) com um chamado para encontrar uma maneira alternativa de criar profissionais de ensino eficientes.

O autor argumenta que, a partir de uma consciência crítica das exigências locais, o(a) professor(a) vai ser capaz de conseguir uma pedagogia da particularidade. Ele chama a atenção para relação intrínseca entre a pedagogia da particularidade e a pedagogia da prática, uma vez que o particular está tão enraizado na prática que esta não será alcançada efetivamente se aquele não for levado em consideração.

Kumaravadivelu (2001) vê como saída para essa questão o encorajamento e a capacitação para que "os próprios professores teorizem a partir de sua prática pedagógica e pratiquem o que eles teorizam" (p. 541). Esse não é um trabalho simples é só pode ser executado se os(as) professores(as) forem capacitados a desenvolver uma série de habilidades que possibilitem que sua prática pedagógica seja um investimento que renda frutos. Tópico amplamente discutido por Kincheloe (1997). 
A história dos aprendizes e professores(as) e o contexto social, político e econômico no qual eles estão inseridos vão influenciar na dinâmica da sala de aula. Fator que não é considerado pelos "burocratas da educação". Dessa forma, a educação deve ser vista como espaço onde se questiona a formação de identidade e a transformação social.

$\mathrm{Na}$ realidade brasileira na qual um(a) professor(a) do ensino fundamental e/ou médio têm uma carga horária em média de 40h, salas lotadas, um salário que, em geral, não é o suficiente para pagar as contas no final do mês e uma série de outros contratempos, parece uma extravagância se falar em atualização por meio das pesquisas científicas publicadas na área (essas são ainda mais inacessíveis se o professor não está vinculado a uma faculdade, ou se esta não oferece programas de pós-graduação) e outras propostas sugeridas pelo Pós-Método, mas o principal objetivo deste artigo é que o(a) professor(a) conheça os principais pressupostos teóricos da área e, por meio de leituras aprofundadas, troca de idéias com colegas e comparação entre a teoria e sua prática, ele(a) entenda que dar aula de LE e muito mais que escolher atividades que motivem os alunos. A união entre experiência, reflexão e a literatura em Lingüística Aplicada podem fazer com que ele(a) seja capaz de identificar quais são suposições que estão por trás de determinada atividade e em que medida elas se adaptam a sua realidade.

A literatura da área oferece muitas informações acerca de estratégias e estilos de aprendizagem. Acredita-se que o conhecimentos e uso dos mesmos vão ser capazes de possibilitar o exercício de dois aspectos essências para essa nova pedagogia: 1 construção da co-responsabilidade do aluno pela sua aprendizagem e 2- reflexão sobre sua aprendizagem e busca de maneiras alternativas para abordá-la. Conforme Kumaravadivelu (2001, p. 546), os aprendizes podem usar inúmeros instrumentos para:

1 - Identificar suas estratégias e estilos de aprendizagem [...] ampliar seu repertório, utilizando estratégias que os aprendizes bem-sucedidos lançam mão, avaliar o resultado de sua aprendizagem através do monitoramento [...] procurar outras oportunidades de praticar a língua estudada.

As opiniões e a perspectiva dos(as) professores(as) devem ser levadas em consideração, no intuito de desenvolver as capacidades críticas destes. Além do mais, Kumaravadivelu (2001, p. 555), argumenta que se deve reconhecer e ajudar os/as 
futuros(as) professores(as) a reconhecerem seu papel enquanto produtores de conhecimento, capacitá-los a refletir a partir de suas crenças e perspectivas, unindo teoria a prática, criar condições para a aquisição de habilidades básicas para análise do discurso de sala de aula, desenvolver pesquisa em conjunto com seus aprendizes, capacitá-los a entender a pedagogia da possibilidade, e aliar o conhecimento fornecido pela literatura em Lingüística Aplicada com sua prática pedagógica:

\begin{abstract}
A pedagogia pós-método [...] impõe um nível extraordinário de responsabilidade sobre todos os participantes, especialmente sobre 0 professor e sobre o formador de professores. Problematizar essa pedagogia identificará algumas preocupações amplas que podem surgir.
\end{abstract}

Dessa maneira, o(a) professor(a) pós-método é autônomo. Essa autonomia está relacionada à implementação de uma teoria, a partir da prática, que responda às especificidades do contexto e à sua condição sócio-política. Essa reflexão deve ser seguida de uma capacidade de teorizar, refletir sobre o que gerou a situação e suas conseqüências para não se incorrer no erro do "achismo". Giroux (1997) também defende tal posição e argumenta que os(as) professores(as) devem ser "tanto teóricos como praticantes" (p. 40). A pesquisa feita pelo(a) professor(a) envolve ficar atento a dinâmica da sala de aula, ver o que funciona ou não, em que grupo, por que motivo; e, a partir daí, poder indicar quais mudanças são necessárias para que a aula alcance os objetivos desejados.

Os formadores de professor(a) tradicionalmente têm tido um papel de transmissores de formulas e teorias deixando os(as) futuros(as) professores(as) a tarefa de reproduzir e aplicar os estudos desenvolvidos pelos primeiros. Isso vai de encontro com a proposta de "se produzir professores(as) auto-direcionados e autodeterminantes" o que é a essência do Pós-Método. "A educação do professor deve ser concebida como uma entidade construída dialógica e continuadamente, envolvendo dois ou mais interlocutores criticamente reflexivos" (Kumaravadivelu, 2001, p. 552).

\title{
CONSIDERAÇÕES FINAIS
}

O Pós-Método faz um chamado para o(a) professor(a) intelectual, mas não um intelectual no sentido tradicional - figura que geralmente se apropria do conhecimento 
alheio e o reproduz na sala de aula. Esse(a) professor(a) deve conhecer a teoria e, a partir de sua prática, ser capaz de refletir sobre o seu contexto, desenvolvendo uma abordagem coerente, esclarecida e que é capaz de se reconstruir e se adaptar às situações, aos contextos e aos objetivos específicos daquela comunidade. Essa não parece ser uma tarefa fácil, porque requer um investimento de tempo, energia, reflexão e principalmente autocrítica, mas certamente vai contribuir para tomadas de decisões surtam efeitos positivos na aprendizagem de LE. Conseqüentemente, esse(a) novo(a) professor(a) pode ser capaz de implementar mudanças na sua prática pedagógica que poderão colaborar na construção de indivíduos ativos e transformadores de sua realidade.

Com base no exposto acima, percebe-se que, numa reforma educacional, os professores(as) e formadores(as) de professores(as) constituem os agentes-chave nessa mudança. Mudança que transcende os materiais e métodos e inclui alterações nas atitudes e crenças dos educadores. Só a partir de reflexões, análises, introspecção, e ação, podem-se diagnosticar problemas e tentar chegar a maneiras específicas de tentar combatê-los.

Assim como afirmaram Brown (1997), Larsen-Freeman (2000), Richards \& Rodgers (2001), os(as) professores(as) experientes e os(as) futuros(as) professores(as) devem conhecer e ser capazes de usar métodos e abordagens de forma flexível e criativa embasados no seu contexto educacional, atividades e objetivos. Apesar do anúncio da morte do método por Allwright em 1990, Richards \& Rodgers (2001, p. 253-4) identificam alguns fatores que influenciaram o ensino de língua no passado e que provavelmente continuarão a fazê-lo:

- Tendências na profissão;

- Inovações lideradas por Gurus;

- Respostas a mudanças tecnológicas;

- Influência de disciplinas acadêmicas;

- Influência das pesquisas;

- Inovações baseadas no aprendiz;

- Tendências intereducacionais;

- Tendências interdisciplinares. 
Em uma profissão na qual a dinâmica de trabalho muda constantemente e o professor(a) está sempre enfrentando novos desafios a fim de conseguir realizar seu trabalho, é de fundamental importância que ele assuma uma postura crítica e ativa para tomar decisões antes, durante e depois das aulas (Bailey, 1996, p. 38). $\mathrm{Na}$ esperança de ensino que também eduque e sirva a quem ele deve servir (Kumaravadivelu, 2001), a escolha de uma pedagogia Pós-Método possibilita que professor(a)-pesquisador(a) possa teorizar e praticar de acordo com a realidade local.

\section{BIBLIOGRAFIA}

ALLWRIGHT, D. The death of the method. Plenary paper for the SGAV Conference, Carleton University: Ottawa, may, 1991.

BAILEY, $K$. The best-laid plans: teachers' in-class decisions to depart from their lesson plans. In: Baley, K. \& Nunan, D. (org.) Voices from the language classroom. New York: Cambridge University Press, p. 15-40, 1996.

BROWN, H. D. Principles of language learning and teaching. Englewood Cliffs, New Jersey: Prentice Hall, 1997.

LARSEN-FREEMAN, D. Techniques and principles in language teaching. Hong Kong: Oxford University Press, 2000.

GIROUX, H. A. Repensando a linguagem da Escola. In: GIROUX, H. A. Os professores como intelectuais: rumo a uma pedagogia crítica da aprendizagem. Artes Médicas: Porto Alegre, p. 33-41, 1997.

. Professores como intelectuais transformadores. In: GIROUX, H. A. Os professores como intelectuais: rumo a uma pedagogia crítica da aprendizagem. Artes Médicas: Porto Alegre, p. 157-164, 1997.

KINCHELOE, J. L. Modernismo e passividade cognitiva da educação técnica do professor. In: KINCHELOE, J. L. A formação do professor como compromisso político: mapeando o pós-modernismo. Artes Médicas: Porto Alegre, p. 11-25, 1997.

KUMARAVADIVELU, B. The post-method: (E)merging strategies for second/foreign language teaching. In: TESOL Quarterly 28, p. 27-48, 1994.

2001.

Toward a postmethod pedagogy. In: TESOL Quarterly 35, p. 537-60, 
PRABHU, N. S. There is no best method - why? TESOL Quarterly 24, p. 161-176, 1990.

RICHARDS, J. C. \& RODGERS, T. Approaches and methods in language teaching. New York: Cambridge University Press, 2001. 